\title{
O DIREITO INTERNACIONAL PRIVADO NOS 50 ANOS DO PROGRAMA DE PÓS-GRADUAÇÃO EM DIREITO DA FACULDADE DE DIREITO DA USP: ESFORÇOS PARA A CONSOLIDAÇÃO DE UMA SUBÁREA DO DIREITO INTERNACIONAL
}

\author{
Gustavo Ferraz de Campos Monaco ${ }^{1}$
}

Introdução, histórico e metodologia

O Programa de Pós-Graduação em Direito mantido pela Faculdade de Direito da Universidade de São Paulo conta 10 áreas de concentração, divididas algumas de suas áreas em subáreas. Cada área tem liberdade para decidir se ofertará subáreas ou não, o que se vincula, muitas das vezes, com a estrutura mantida pelo Departamento de ensino respectivo.

Muito embora não seja obrigatório o espelhamento entre Área de Concentração e Departamento, haja vista a manutenção - atualmente - de uma área transversal, com temática que congrega variados interesses e atrai docentes orientadores de diversos departamentos e até mesmo de outras Unidades da USP (Direitos Humanos), a verdade é que a tradição do Programa é a da existência de nove áreas que correspondem, com pequenas variações, aos Departamentos de Ensino que compõem a Faculdade de Direito. É este o caso, por exemplo, da área de Direito Internacional, que corresponde ao antigo Departamento de Direito Internacional, rebatizado - no começo do presente século - de Departamento de Direito Internacional e Comparado, adjunção que não se espelha - ao menos não por ora - no Programa de Pós-Graduação.

$\mathrm{Na}$ área de Direito Internacional, que é uma área suportada sobretudo pelos docentes vinculados ao Departamento de Direito Internacional e Comparado da Faculdade, mas não só, ${ }^{2}$ são ofertadas, desde há alguns anos, três subáreas de formação: direito internacional público, direito internacional privado e direito do comércio internacional, que correspondem aos três cargos de Professor Titular tradicionalmente vinculados ao Departamento.

Professor Titular de Direito Internacional Privado da Faculdade de Direito da Universidade de São Paulo. É o caso de docentes que, tendo composto o Departamento, acabaram se transferindo, por concurso público, para outros Departamentos ou até mesmo para outras Unidades de Ensino da USP para exercerem, todos eles, as funções de Professores Titulares. No primeiro grupo pode-se indicar os Professores Celso Lafer (que se transferiu para o Departamento de Filosofia e Teoria Geral do Direito) e Hermes Marcelo Huck (que se transferiu para o Departamento de Direito Econômico, Financeiro e Tributário). No segundo grupo, contam-se os Professores Pedro B. de Abreu Dallari (que se transferiu para o Instituto de Relações Internacionais) e Umberto Celli Junior (que se transferiu para a Faculdade de Direito de Ribeirão Preto). 
Nos primeiros anos a partir da introdução das subáreas, em 2005, estas serviam basicamente para a segunda fase de seleção dos novos pós-graduandos, uma vez que o Departamento fornecia três listas de dez pontos para que os candidatos realizassem a prova de conhecimentos jurídicos, dissertando acerca do ponto sorteado. Neste modelo, os candidatos à área de Direito Internacional deveriam, então, dissertar a respeito do tema indicado por álea, optando por aquele que entendessem melhor preparados (se o de internacional público, internacional privado ou comércio internacional). Mas a elaboração de dissertação acerca de ponto de uma subárea não os vinculava àquela, podendo, assim, apresentar projeto de pesquisa em outra subárea e candidatar-se à orientação de docente com linha de pesquisa que não coincidia, necessariamente, com a subárea em que realizara a prova.

Mais recentemente, a partir do processo seletivo realizado em 2017 para ingresso em 2018, as subáreas passaram a ser vinculativas e mandatórias, isto é: uma vez feita a inscrição, o candidato fica vinculado àquela subárea escolhida. Ao mesmo tempo, o docente que abre vaga numa subárea não pode ser indicado por candidato inscrito em outra. Além disso, ao invés de uma dissertação sobre ponto previamente conhecido, os candidatos são instados a responder questões afetas à subárea a partir de listagem bibliográfica previamente selecionada pelo Departamento para cada divisão.

Tratou-se de mudança saudável no processo de seleção, porquanto geradora de maior aderência à pesquisa dos docentes afetos à subárea de verdadeiro interesse do candidato, evitando-se uma flutuação indesejável ou o desenvolvimento de pesquisa a respeito de cujos fundamentos os candidatos não necessariamente possuem.

Tais mudanças, todavia, foram realizadas de forma paulatina, sem romper abruptamente com uma tradição que remonta à própria formação do Departamento de Direito Internacional. A manutenção de um Departamento voltado ao estudo, ao ensino e à pesquisa exclusiva do Direito Internacional e de forma transversal e integrada pode ser referida como uma experiência que se constitui numa raridade em universidades mundo afora.

Desde seus primórdios, os docentes que compunham o Departamento procuraram implantar mecanismo de não especializar os professores, garantindo que todos pudessem lecionar, orientar e pesquisar em todas as temáticas de interesse para o Departamento. ${ }^{3} \mathrm{O}$ mesmo ocorria nos concursos a Livre-Docência. Tal estratégia exige

3 No meu mestrado na Universidade de Coimbra sob orientação de Rui Manuel Moura Ramos, por exemplo, desenvolvi pesquisa e redigi dissertação afeta ao Direito Internacional Público, embora aborde alguns aspectos de Direito Internacional Privado. A dissertação está publicada sob as seguintes referências: MONACO, Gustavo Ferraz de Campos. A Declaração Universal dos Direitos da Criança e seus sucedâneos internacionais: tentativa de sistematização. Coimbra: Coimbra (Coleção Stvdia Ivridica, v. 80), 2004; MONACO, Gustavo Ferraz de Campos. A proteção da criança no cenário internacional. Belo Horizonte: Del Rey, 2005. 
dos candidatos a postos de Professor Doutor e ao título de Livre-Docentes, conhecimento transversal das diversas subáreas. ${ }^{4}$ Apenas os Professores Titulares têm, em tese, uma especialização, e cada uma das cadeiras refere-se a uma das subáreas. Em tese porque nada impede que o Titular de uma subárea ministre aulas ou oriente em outra. Mas, atualmente, temos procurado manter nossas atividades afetas às subáreas específicas, inclusive como forma de consolidar a pesquisa em cada qual.

No que concerne especificamente à subárea de Direito Internacional Privado, notou-se nos últimos anos um aumento sensível no número de candidatos que se inscrevem na subárea, o que demonstra que as mudanças empreendidas no processo de seleção foram positivas.

Com a intenção de tentar apontar as razões que possam explicar o aumento na demanda por vagas de pós-graduação específicas para a subárea de direito internacional privado, o presente artigo busca analisar os quantitativos de produção da subárea de direito internacional privado, dividindo-os em quatro quadrantes: (i) antes da institucionalização do PPGD, (ii) em seu primeiro quartel, (iii) no segundo quartel e (iv) a projeção de seu futuro, à guisa de conclusão.

Para tanto, e do ponto de vista metodológico (a pandemia da Covid-19 certamente dificultou o acesso aos trabalhos acadêmicos mais antigos disponíveis na Biblioteca da Faculdade), procedeu-se à busca no Dedalus (Banco de Dados Bibliográficos da USP), ${ }^{5}$ dos termos "Direito Internacional" e "Direito Internacional Privado". Limitou-se a busca à Base da Faculdade de Direito [Base para Busca: FD Fac. Direito] e impôs-se como filtro de busca a Base relativa às Teses [Bases de Dados: Teses] e que congloba as dissertações de mestrado, teses de Doutorado, teses de LivreDocência e Teses apresentadas em concursos para provimento de Cátedras ou de cargos de Titular.

A pesquisa da expressão "Direito Internacional" resultou em 647 entradas, ao passo que a pesquisa da expressão "Direito Internacional Privado" resultou em 71 entradas. Por comparação, procedeu-se à busca da expressão "Direito Internacional Público" e obteve-se 93 resultados. "Direito do Comércio Internacional”, por sua vez, resultou em 21 indicações de dissertações ou teses.

Tais dados indicam que os bibliotecários da Faculdade de Direito da USP, sobretudo no passado (mas não só), catalogavam as dissertações e teses sob a expressão "Direito Internacional" e sem a preocupação de indicar a subárea respectiva. Por tal

\footnotetext{
4 Em ambos os concursos a que me submeti, curiosamente, foram sorteados pontos de direito internacional público e de direito internacional privado. No concurso de ingresso, ao tempo em que realizei prova escrita a respeito de internacional público, ministrei aula (prova didática) de privado. Na Livre-docência, inverteu-se: privado foi tema da prova escrita e a aula versou ponto de internacional público.

5 Disponível em: http://dedalus.usp.br/F?RN=25342389. Acesso em: 22 jan. 2021.
} 
razão, decidiu-se revisar a ficha catalográfica de todos os 647 resultados obtidos na pesquisa mais ampla revisão esta que foi feita a partir do título e, quando disponível, do resumo do trabalho acadêmico.

A título meramente ilustrativo, veja-se, abaixo, a ficha catalográfica da Tese que apresentei em 2018 para o concurso para Provimento de Cargo de Professor Titular de Direito Internacional Privado ${ }^{6}$ e que, não obstante, indica como assunto apenas a expressão "Direito Internacional":

\begin{tabular}{ll} 
No. Registro & 002981735 \\
Tipo de material & TESE \\
\hline Entrada Principal & 9Monaco, Gustavo Ferraz de Campos \\
\hline Título & $\underline{\text { Conflitos de leis no espaço e lacunas (inter) sistêmicas. }}$ \\
\hline Imprenta & São Paulo, 2018, \\
\hline Descrição & 299 p. \\
\hline Idioma & Português \\
\hline Nota Tese/Diss & Professor Titular \\
\hline Nota Local & Direito Internacional e Comparado \\
Departamento & DIN DIREITO INTERNACIONAL \\
Assunto & 9DIREITO INTERNACIONAL \\
\hline Unidade USP & FD -- FACULDADE DE DIREITO
\end{tabular}

Fonte: http://dedalus.usp.br/F/5834ID55SQG1D371JHPY3CQPR9RUVGTBCJ81TU8B4E29J37 $\mathrm{HNN}-08118$ func $=$ full-set-set\&set_number $=005038 \&$ set_entry $=000003 \&$ format $=999$

Como forma de garantir uma dupla filtragem, procedeu-se à busca do nome de todos os orientadores credenciados na área de Direito Internacional no Programa de Pós-Graduação mantido pela Faculdade de Direito da USP. Isto porque nota-se que teses e dissertações orientadas por docentes credenciados em outras áreas de concentração apareceram, por vezes, na relação de dados obtidos com as pesquisas por palavraschave, o que demonstra o interesse pela temática internacional privada ao menos nas áreas de concentração em direito civil, direito comercial e direito do trabalho, como se demonstrará adiante.

6 MONACO, Gustavo Ferraz de Campos. Conflitos de Leis no Espaço e Lacunas Inter(sistêmicas). São Paulo: Quartier Latin, 2019. 
1. A produção acadêmica na subárea antes da institucionalização do PPGD-FDUSP

Anteriormente à institucionalização do Programa de Pós-Graduação da Faculdade de Direito da USP, nos termos do Parecer Sucupira, ${ }^{7}$ a busca pela expressão "Direito Internacional Privado" na Base relativa às Teses [Bases de Dados: Teses] retorna um total de oito registros, dos quais dois referem-se a teses de Doutorado, sendo os outros seis referentes a Teses de Livre-Docência (duas) ou Provimento de Cátedra (quatro).

A mais antiga das entradas data de 1934 e se refere à tese de Doutorado apresentada por Edmundo Auerning Burle e que tem por título "Direito internacional privado: a nova tendência do direito internacional privado, representada pela teoria de Frankenstein", tese com 53 páginas. Embora pouco se saiba a respeito do autor e não se tenha tido acesso à tese em razão da pandemia, pode-se indicar que a temática era bastante atual para a época em que escrita, uma vez que Ernst Frankenstein (Dortmund, 1881 - Londres, 1959) se encontrava no auge de sua produção literária. ${ }^{8}$

O segundo registro diz respeito à Tese de Livre-Docência apresentada por Luis Antonio da Gama e Silva, em 1944, e que versa sobre a "Ordem pública em direito internacional privado". Do mesmo autor, é o terceiro registro, datado de 1952, obra intitulada "Qualificações em direito internacional privado", com 259 páginas. Trata-se da tese que apresentou para o primeiro concurso para provimento da Cátedra de Direito Internacional Privado, do qual sagrou-se o vencedor e que contou com teses apresentadas por outros três candidatos. ${ }^{9}$

A antiga Cátedra de Direito Internacional fora cindida nos anos 1940 e seu então ocupante, o Professor Braz Arruda optou por se manter vinculado ao ensino do Direito Internacional Público. Antonio de Sampaio Doria, que vinha ministrando, cumulativamente com o curso de Direito Constitucional, de que era o Catedrático, ${ }^{10}$ também o curso de Direito Internacional Privado no Bacharelado, ainda que de forma

7 A Pós-Graduação foi reformulada no Brasil a partir do Parecer 977/65, disponível em: https://www.scielo. br/pdf/rbedu/n30/a14n30.pdf, relatado por Newton Sucupira no âmbito do antigo Conselho de Educação Superior do MEC.

8 Veja-se, sobre o autor, em língua portuguesa, COELHO DE MENDONÇA, Pio. Breve ensaio sobre uma construção de Ernst Frankenstein. Revista da Ordem dos Advogados, Lisboa, a. 7, ns. 1-2, p. 65-127. Disponível em: https://portal.oa.pt/upl/\%7B0AFE613C-DDA6-4FE4-A6EF-C8350CCA1DE7\%7D.pdf. Acesso em: 23 jan. 2021.

9 Corrijo, assim, a informação que fiz constar da "Nota do autor" publicada em MONACO, Gustavo Ferraz de Campos. Conflitos de Leis no Espaço e Lacunas Inter(sistêmicas). São Paulo: Quartier Latin, 2019, p. 22, a respeito de não ter havido disputa naquele concurso, pelo que me penitencio.

10 MACHADO JUNIOR, Armando Marcondes. Cátedras e Catedráticos. São Paulo: Associação dos Antigos Alunos da Faculdade de Direito da USP, 2010. 
esporádica, ${ }^{11}$ assumiu a cadeira de Internacional Privado, para a qual veio definitivamente transferido. $^{12}$

Também de 1952 é a entrada seguinte, referente à Tese apresentada para provimento de Cátedra por Luís Araújo Correa de Brito, que continuou Professor Livre Docente da Faculdade depois de ter sido vencido por Gama e Silva. ${ }^{13}$ Tal tese, com 187 páginas, cuidava "Do limite à extraterritorialidade do direito estrangeiro no código civil brasileiro".

De 1953 consta entrada de tese apresentada para Provimento de Cátedra, de autoria de Nicolau Nazo (que viria a ser futuramente, catedrático de Direito Civil), intitulada "A determinação do domicílio no direito internacional privado brasileiro" e que conta 80 páginas. A data diferente da dos demais candidatos pode ser devida a um equívoco de digitação ou à circunstância do período de inscrição no Concurso ter se estendido pelos dois anos.

Nova entrada, a sexta, só se vai encontrar em 1967, com a Tese apresentada para obtenção de seu segundo título de Livre-Docente, por Irineu Strenger. Em 1964 o autor obtivera seu primeiro título na área de Filosofia e Teoria Geral do Direito, com a apresentação da tese intitulada "Da dogmática jurídica: contribuição do conselheiro Ribas à dogmática do direito civil brasileiro". Para a área de Direito Internacional Privado, Strenger escreveu a tese "Da autonomia da vontade em direito internacional privado", com 230 páginas, o que vai habilitálo a concorrer, em 1971, à cadeira de Direito Internacional Privado, com a tese intitulada "Regime jurídico da reparação do dano em Direito Internacional Privado", sucedendo a Gama e Silva.

Entre a Livre-Docência e a tese para a disputa da Titularidade de Irineu Strenger, consta o registro, datado de 1967, da segunda tese de Doutorado registrada antes da institucionalização do PPGD. De autoria de José Roberto Franco da Fonseca, que foi Professor do Departamento (mas nunca orientou na subárea de Internacional

11 CASELLA, Paulo Borba. Missão do Direito Internacional no mundo pós-moderno - reflexão pelos 190 anos do direito internacional nas Arcadas. Revista da Faculdade de Direito da USP. São Paulo, v. 112, p. 785-821, 2017, p. 804 e 806.

12 Para mais detalhes, além das referências constantes das duas notas anteriores, veja-se MONACO, Gustavo Ferraz de Campos. História e Futuro do Direito Internacional Privado Brasileiro. MORAU, Caio (org). História e Futuro do Direito Brasileiro: estudos em homenagem a Ignacio Maria Poveda Velasco. São Paulo, LiberArs, p. 171-180.

13 Em 1959, conforme atestam as folhas iniciais da Revista da Faculdade de Direito daquele ano, além do catedrático de Direito Internacional Privado, Luis Antonio da Gama e Silva, a Faculdade contava com três Professores Livre-Docentes que se dedicavam à disciplina: Nicolau Nazo, Antonio Chaves e Luís Araújo Corrêa de Brito. Os dois primeiros tornaram-se, posteriormente, Professores Catedráticos de Direito Civil. Disponível em: http://www.obrasraras.usp.br/jspui/bitstream/123456789/3141/1/Revista_FD_vol54_ fasc2_1959.pdf. Acesso em: 23 jan. 2021. 
Privado, como se verá), a tese "Contra a renúncia e a devolução: Direito Internacional Privado" tem 146 páginas.

A busca pela expressão "Direito Internacional", por seu turno, traz 16 registros. Dentre eles revela-se a tese para provimento de cátedra apresentada, em 1952, por Antonio Chaves, para o concurso no qual Gama e Silva sagrou-se vencedor. Intitulada "Proteção internacional do direito autoral de radiodifusão", a tese apresenta 662 páginas. Descontadas as 8 produções anteriormente referidas, verifica-se que as outras sete entradas do sistema bibliográfico se referem ao direito internacional público, das quais, um Mestrado (José Thales Nunes Ferreira, 1967), um Doutorado (Geraldo Bezerra de Moura, 1968), uma Livre-Docência (Vicente Marotta Rangel, 1954), uma tese para provimento de cátedra (Vicente Marotta Rangel, 1965) e duas com graus não identificados (Celso Brandt, 1951, e Freitas Guimarães, 1912).

2. A produção acadêmica na subárea no primeiro quartel do PPGD-FDUSP (19711996)

O Programa de Pós-Graduação da Faculdade de Direito (PPGD) da Universidade de São Paulo (FDUSP), vinculado à Pró-Reitoria de Pós-Graduação da USP, foi criado em 1969 e encontra-se em ininterrupta atividade desde 1971, sendo, nesse sentido, o mais antigo Programa de Pós-Graduação em Direito em funcionamento no país adequado aos termos em que vazado o Parecer 977/65, relatado por Newton Sucupira no âmbito do antigo Conselho de Educação Superior do MEC.

No primeiro quartel do programa, cujo encerramento coincide com meu primeiro ano na Graduação da Faculdade de Direito, a busca pela expressão "Direito Internacional Privado" na Base relativa às Teses [Bases de Dados: Teses] retorna apenas três registros, sendo uma dissertação de mestrado (1990), uma tese de Doutorado (1994) e uma tese apresentada para concurso de Professor Titular (1993), esta apresentada no concurso que indicou o sucessor de Irineu Strenger, João Grandino Rodas, autor da Tese "Evolução do liame entre sociedade comercial e Estado", com 497 páginas. Poucos anos antes da aposentadoria de Irineu Strenger, no entanto, o Departamento obteve um novo posto de Professor Titular, cujo concurso aberto para a subárea do Direito do Comércio Internacional, encontrou apresentada a Tese "Vida dos contratos internacionais", escrita por Luiz Olavo Baptista, em 1992. Esta tese, todavia, está catalogada com referência apenas ao termo de busca "Direito Internacional".

Assim é que se procedeu também à busca, na mesma Base de Dados, pela expressão "Direito Internacional", que retornou 94 itens, muitos dos quais, afetos ao Direito Internacional Privado. 
A primeira tese de Doutorado afeta ao Direito Internacional Privado é datada de 1972 e foi apresentada por Octanny Silveira da Mota, sob orientação de Vicente Marotta Rangel e Irineu Strenger, então os dois Titulares do Departamento. Intitulada "Responsabilidade civil do transportador aéreo internacional por danos a integridade pessoal do passageiro", a tese conta 176 páginas.

A primeira dissertação de Mestrado com vinculação potencial ao Direito Internacional Privado aparece datada de 1979. Escrita por Araminta de Azevedo Mercadante, sob a orientação de Vicente Marotta Rangel, a dissertação "Contribuição ao estudo da arbitragem comercial internacional: a convenção arbitral", de 412 páginas, inaugura o estudo de um tema recorrente nos anos subsequentes e que aparece tanto vinculado ao Direito Internacional Privado quanto ao Direito do Comércio Internacional e que, por vezes, guarda vinculação com o Direito Internacional Público: a arbitragem. ${ }^{14}$

Outros dois temas, pelo menos, guardam essa vinculação múltipla e potencial com as diversas subáreas do departamento e que dificultam cravar - sem conhecimento do todo da pesquisa - se a abordagem é afeta a esta ou àquela subárea do Direito Internacional, a saber: as imunidades de jurisdição e execução (que podem estar vinculadas ora ao Direito Internacional Público, ora ao Direito Internacional Privado ${ }^{15}$ ) e os contratos internacionais (que podem dar origem a uma abordagem típica do Direito Internacional Privado ou do Direito Internacional do Comércio $\left.{ }^{16}\right) .{ }^{17}$

Em 1980, são defendidas duas dissertações de mestrado com vinculação ao Direito Internacional Privado, a saber: "Condição jurídica dos navios mercantes estrangeiros em mar territorial”, de Zilah Maria Victor Rodrigues, 74 páginas, sob orientação de Irineu

14 É o caso, por exemplo, das seguintes teses e dissertações apresentadas no primeiro quartel: José Carlos de Magalhães. Arbitragem internacional entre Estado e particular (Doutorado, sob orientação de Vicente Marotta Rangel), 1983, 241 p.; Luise Gisela Lydia Schmalz. Convenção arbitral nas arbitragens entre particulares: instituição do tribunal arbitral (Mestrado, sob orientação de João Grandino Rodas), 1989, $277 \mathrm{p}$.

15 É o caso, por exemplo, da tese de Livre-Docência de Guido Fernando Silva Soares, Das imunidades de jurisdição e de execução, 1980, $282 \mathrm{p}$.

16 É o caso, por exemplo, das seguintes teses e dissertações apresentadas no primeiro quartel do PPGD: Maria Luiza Machado Granziera. Equilíbrio instável: uma colaboração ao estudo dos contratos internacionais de fornecimento de equipamentos a longo prazo (Mestrado, sob orientação de João Grandino Rodas), 1988, 186 p.; Jorge David Barrientos Parra. Principios dos contratos internacionais (Mestrado, sob orientação de Irineu Strenger), 1989, 354 p.; Luiz Alfredo Ribeiro da Silva Paulin. Contribuição ao estudo dos contratos internacionais (Doutorado, sob orientação de Luiz Olavo Baptista), 1994, 374 p.; Maurício Curvelo de Almeida Prado. Contrato internacional de transferência de tecnologia (patente e know-how) (Mestrado, sob orientação de Luiz Olavo Baptista), 1995, 185 p.; Nadia de Araujo. Autonomia da vontade e contratos internacionais (Doutorado, sob orientação de João Grandino Rodas), 1996, 287 p.

17 Por tal razão, só se fará referência explícita a tais trabalhos no corpo do texto quando o título ou o Resumo (quando disponível) permitirem antever a vinculação específica ou quando se tratar de tese apresentada por orientador do PPGD que ministre aulas de disciplina vinculada à subárea. 
Strenger, e "Contribuição ao estudo das empresas multinacionais", de Saul de Moraes Bonilha Filho, 172 páginas, sob orientação de Vicente Marotta Rangel. ${ }^{18}$

Em 1981, encontra-se referência à tese de Doutorado elaborada por Hermes Marcelo Huck, que viria a ser professor da disciplina por longos anos até ser indicado como Titular do Departamento de Direito Econômico, Financeiro e Tributário. Sob orientação de Irineu Strenger, foi apresentada a tese "Contratos com o Estado: aspectos de Direito Internacional”, de 238 páginas.

Entre 1983 e 1994, seguem-se outras três dissertações de mestrado orientadas por Irineu Strenger, também com temas atinentes ao transporte internacional: "Segurança do transporte aéreo e suas consequências jurídicointernacionais", com 70 páginas, foi defendida por Samuel Schneider Netto (1983), Sergio Roberto Alonso apresenta "Responsabilidades não legisladas decorrentes do transporte aéreo internacional”, com 56 páginas (1988) e Maria Esther Fernandez Alvarez defende "Contrato de transporte aéreo e a responsabilidade do transportador", com 240 páginas (em 1994).

Também é o caso da tese de Doutorado "Apoderamento ilícito de aeronaves", de autoria de Paulo Borba Casella, atual Professor Titular de Direito Internacional Público do Departamento. Sua tese, de 696 páginas, foi entregue em 1986 e contou também com a orientação de Irineu Strenger.

Antes, em 1985, encontra-se referência à dissertação de mestrado "Estudo sobre os conflitos de leis de acordo com os precedentes do direito norte-americano", elaborada por Roseméa de Souza Smart, com 165 páginas e que foi orientada por Irineu Strenger e João Grandino Rodas.

Em 1989 é a vez de aparecerem duas dissertações de mestrado na subárea de Direito Internacional Privado orientadas, ambas, por Guido Fernando Silva Soares, que viria a suceder a Vicente Marotta Rangel e anteceder a Paulo Borba Casella como Titular de Direito Internacional Público. A dissertação “Aplicação do direito estrangeiro no processo civil pelos tribunais suíços em relação ao Brasil" foi apresentada por Beat Walter Rechsteiner, em 2 volumes (não há indicação do total de páginas no registro bibliográfico) e a dissertação "Contribuição à análise da lei aplicável aos contratos internacionais", com 212 páginas, foi defendida por Carlos Eduardo Silva Marcatto.

Em 1990 mais uma dissertação orientada por Guido Soares é apresentada por Helena Maria de Jesus Cravo Roxo, com 132 páginas, e catalogada com a indicação de pertencer à temática do Direito Internacional Privado. Seu título é "Estrangeiro frente a justiça brasileira: pretensão à tutela jurisdicional civil”. 18 Pese embora a possibilidade de que este trabalho tenha abordagem de exclusivo interesse para o direito
internacional público. 
Quatro anos mais tarde, em 1994, a tese de Doutorado de Carlos Eduardo de Abreu Boucalt, orientada por João Grandino Rodas, é também catalogada como pertencente à subárea do Direito Internacional Privado. Tendo por objeto a "Doutrina dos direitos adquiridos na perspectiva do direito internacional privado contemporâneo", a tese apresenta 282 páginas.

Um ano antes, Maristela Basso, atualmente Professora Associada do Departamento de Direito Internacional e Comparado e que ministra aulas no Curso de Graduação da disciplina de Direito Internacional Privado, apresentou e defendeu, sob orientação de Luiz Olavo Baptista, a tese "Negociação e formação dos contratos internacionais do comércio: direito comparado e prática dos negócios", com 392 páginas.

Por fim no âmbito deste primeiro quartel, em 1996, aparece a tese de doutorado de Esther Miriam Flesh, orientada por Irineu Strenger, e que cuida, em 296 páginas, da "Publicidade transfronteiriça como ato de concorrência desleal e o direito aplicável", que poderia ser classificada no âmbito do Direito do Comércio Internacional. Não obstante, a referência explícita ao direito aplicável justifica seu enquadramento, para os propósitos da presente pesquisa, na subárea do Direito Internacional Privado.

Conclui-se, assim, que neste primeiro quartel do PPGD mantido pela FDUSP, a subárea de Direito Internacional Privado foi responsável pela elaboração de quatorze dissertações de Mestrado e nove teses de Doutorado. Além disso, uma tese de Livre-Docência e duas outras apresentadas a concursos para provimento de cargos de Professor Titular nas subáreas de Direito do Comércio Internacional e de Direito Internacional Privado foram apresentadas à Faculdade de Direito da USP, contribuindo para o aprofundamento dos temas afetos a esta subárea.

3. A produção acadêmica na subárea no segundo quartel do PPGD-FDUSP (19972021)

No segundo quartel do programa, cujo encerramento coincide com o ano em curso, mas cujos dados estão disponíveis no site da Biblioteca apenas até 2019, a busca pela expressão "Direito Internacional Privado" na Base relativa às Teses [Bases de Dados: Teses] retorna sessenta registros (contra os três do quartel anterior).

Dentre estes, conta-se uma tese apresentada em concurso para obtenção do Título de Livre-Docente, em 2012, por Gustavo Ferraz de Campos Monaco, cuja tese, intitulada "Aplicação do direito estrangeiro entre controle intrínseco e controle extrínseco" possui 123 páginas e foi catalogada como sendo afeta ao Direito Internacional Privado. ${ }^{19}$ Outra tese foi apresentada ao Departamento de Direito Internacional, em 1998,

\footnotetext{
19 MONACO, Gustavo Ferraz de Campos. Controle de Constitucionalidade da Lei Estrangeira. São Paulo: 
com vistas à obtenção do título de Livre-Docente, por Beat Walter Rechsteiner, versando sobre "Direito falimentar internacional e Mercosul", em 242 páginas. O candidato foi aprovado, por maioria, e a tese foi classificada exclusivamente como direito falimentar.

Uma outra, apresentada em concurso para Professor Titular, em 2018, embora classificada genericamente como sendo de "Direito Internacional", aparece na pesquisa porquanto contenha, em seu título, explícita referência ao nome da subárea. "A construção do direito internacional privado no século XXI: heterogeneidade e coerência", de autoria de André de Carvalho Ramos, possui 676 páginas e foi apresentada pelo autor no concurso aberto para a sucessão de João Grandino Rodas.

Para o mesmo concurso, inscreveu-se ainda o candidato Gustavo Ferraz de Campos Monaco, cuja tese, intitulada "Conflitos de leis no espaço e lacunas (inter)sistêmicas", com 299 páginas, foi classificada apenas sob a expressão "Direito Internacional", tendo sido este o candidato indicado pelos examinadores, por unanimidade, para o preenchimento do cargo.

Do mesmo modo como a pesquisa foi realizada no caso do quartel anterior, também neste quartel procedeu-se a nova busca, circunscrita ao termo mais amplo "Direito Internacional", o que resultou na ampliação dos resultados para 540 referências de dissertações e teses, muitos dos quais, atinentes também ao Direito internacional Privado.

Como ocorreu no quartel anterior, os temas relativos à arbitragem internacional, ${ }^{20}$ que pode ser afeto às subáreas do direito internacional privado, do

Quartier Latin, 2013.

20 É o caso, por exemplo, das seguintes teses e dissertações: Selma Maria Ferreira Lemes. Os princípios jurídicos da independência e da imparcialidade do árbitro: abordagem à luz do direito internacional e comparado (Mestrado, sob orientação de Hermes Marcelo Huck), 2000, 237 p.; Plínio José Lopes Shiguematsu. A arbitragem comercial internacional e seus campos de regência (Mestrado, sob orientação de Guido Fernando Silva Soares), 2002, 164 p.; Ana Cristina Azevedo Pontes de Carvalho. A Convenção de Nova Iorque no ordenamento jurídico brasileiro (Mestrado, sob orientação de Araminta de Azevedo Mercadante), 2005, 148 p. (ver a nota 21); Ricardo Ramalho Almeida. Arbitragem comercial internacional e ordem pública (Mestrado, sob orientação de Paulo Borba Casella), 2005, 268 p.; Jeanlise Velloso Couto. Arbitro e Estado: interesses divergentes? (Mestrado, sob orientação de Paulo Borba Casella), 2007, 145 p.; Renato Lazzarini. Tutelas urgentes na arbitragem internacional (Mestrado, sob orientação de João Grandino Rodas), 2008, 114 p.; Eduardo Damião Gonçalves. Arbitrabilidade objetiva (Doutorado, sob orientação de José Carlos de Magalhães), 2008, 230 p.; Adriana Braghetta. Laudo arbitral na sede da arbitragem e consequências internacionais: visão a partir do Brasil (Doutorado, sob orientação de Luiz Olavo Baptista), 2008, 338 p.; Debora Visconte. A jurisdição dos árbitros e seus efeitos (Mestrado, sob orientação de José Carlos de Magalhães), 2009, 140 p.; Cristina Saiz Jabardo. Extensão da cláusula compromissória na arbitragem comercial internacional: o caso dos grupos societários (Mestrado, sob orientação de Luiz Olavo Baptista), 2009, 125 p.; Martim Della Valle. Da decisão por equidade na arbitragem comercial internacional (Doutorado, sob orientação de Luiz Olavo Baptista), 2009, 440 p.; Thiago Marinho Nunes. Análise dos efeitos da prescrição extintiva na arbitragem interna e internacional, com visão a partir do direito brasileiro (Doutorado, sob orientação de Paulo Borba Casella), 2011, 471 p.; Fabio Giorgi Infante. A Aplicação da boa-fé na arbitragem internacional (Mestrado, sob orientação de Luiz Olavo Baptista), 2011, 142 p.; Priscila Knoll Aymone. A problemática dos procedimentos paralelos: os princípios da litispendência e da coisa julgada em arbitragem internacional (Mestrado, sob orientação 


\section{direito internacional público ou do direito do comércio internacional, assim como o tema atinente aos contratos internacionais, ${ }^{21}$ que pode guardar vinculação ora com o direito do comércio internacional, ora com o tema do direito internacional privado, porquanto}

de Luiz Olavo Baptista), 2011, 227 p.; Flávia Foz Mange. Processo arbitral transnacional: reflexões sobre as normas que regem os aspectos procedimentais da arbitragem (Doutorado, sob orientação de José Carlos de Magalhães), 2012, 331 p.; Ricardo Medina Salla. Arbitragem e administração pública: Brasil, Argentina, Uruguai e Paraguai (Mestrado, sob orientação de Umberto Celli Junior), 2013, 162 p.; Clávio de Melo Valença Filho. A arbitragem em juízo (Doutorado, sob orientação de Maristela Basso), 2015, 288 p.; Rodrigo Araujo Gabardo. A insuficiência de recursos financeiros na instauração da arbitragem comercial: efeitos no direito brasileiro a partir de uma perspectiva comparada (Mestrado, sob orientação de José Augusto Fontoura Costa), 2014, 160 p.; Fernanda Sirotsky Scaletscky. O consensualismo e a arbitragem internacional (Mestrado, sob orientação de Maristela Basso), 2016, 168 p.; Eliana Buonocore Baraldi. Iura novit cúria em arbitragem internacional (Mestrado, sob orientação de José Carlos de Magalhães), 2016, 172 p.; Patricia Maria da Silva Gomes. A sentença arbitral estrangeira anulada na origem à luz dos direitos brasileiro e francês (Mestrado, sob orientação de José Augusto Fontoura Costa), 2018, 139 p.; Naíma Perrella Milani. Arbitragem de investimentos e meio ambiente (Mestrado, sob orientação de Elizabeth de Almeida Meirelles), 2019, 186 p.; Rodrigo Araujo Gabardo. A existência, validade e eficácia da convenção de arbitragem: uma contribuição para o estudo de sua natureza jurídica (Doutorado, sob orientação de José Augusto Fontoura Costa), 2019, 198 p.

21 É o caso, por exemplo, das seguintes teses e dissertações: José Cretella Neto. Do contrato internacional de franchising (Mestrado, sob orientação de José Carlos de Magalhães), 1999, 247 p.; Paulo Luiz de Toledo Piza. O contrato de resseguro: tipologia, formação e direito internacional (Doutorado, sob orientação de Paulo Borba Casella), 2001, 572 p.; Marcelo Mansur Haddad. O resseguro internacional (Doutorado, sob orientação de Guido Fernando Silva Soares), 2001, 292 p.; Daniela Zaitz. Knowhow: fato valor e norma: a busca de um equilibrio no direito internacional (Doutorado, sob orientação de Luiz Olavo Baptista), 2003, 238 p.; Sandra Medeiros Proença de Gouvêa. Pagamentos internacionais por meios eletrônicos: alguns problemas jurídicos (Mestrado, sob orientação de Luiz Olavo Baptista), 2003, 152 p.; Lauro da Gama e Souza Junior. Os princípios do Unidroit relativos aos contratos do comércio internacional: teoria e prática de uma perspectiva pós-positivista (Doutorado, sob orientação de João Grandino Rodas), 2004, 436 p.; Mariana Mendes Medeiros. Cláusulas de declarações e garantias nos contratos internacionais de aquisição de empresas ou ativos (Mestrado, sob orientação de Luiz Olavo Baptista), 2006, 283 p.; Ana Paula Pinheiro Schedel. O risco da coisa nas compras e vendas internacionais de bens móveis corpóreos (Mestrado, sob orientação de Luiz Olavo Baptista), 2007, 247 p.; Flavia Ferraz. Joint ventures internacionais: aspectos de sua formação, características e término (Mestrado, sob orientação de Luiz Olavo Baptista), 2007, 164 p.; Alexandre Buono Schulz. Os contratos comerciais internacionais na sociedade pós-industrial: reflexões sobre a nova lex mercatoria (Mestrado, sob orientação de Maristela Basso), 2010, 205 p.; Leandro Tripodi. $O$ direito uniforme da venda no século 21: caducidade e renovação da CISG (Doutorado, sob orientação de Maristela Basso), 2014, 229 p.; Alexandre Buono Schulz. A boa-fé nos contratos comerciais internacionais (Doutorado, sob orientação de Maristela Basso), 2014, 199 p.; Roberta Ribeiro Oertel. Le contrat international de distribution en Droit français et brésilien (Doutorado, com duplatitulação com a Universidade de Estrasburgo, França, sob orientação de Jochen Bauerreis e Paulo Borba Casella), 2014, 494 p.; Lígia Espolaor Veronese. A Convenção de Viena de 1980: substituição e complementação ao direito contratual brasileiro no tratamento dos contratos de compra e venda (Mestrado, sob orientação de Umberto Celli Junior), 2016, 170 p.; Débora Visconte. Contratos de longa duração: alterações de circunstâncias no direito internacional (Doutorado, sob orientação de José Carlos de Magalhães), 2017, 265 p.; Vera Cecília Monteiro de Barros. Previsibilidade do dano contratual como critério limitador de responsabilidade no direito do comércio internacional (Doutorado, sob orientação de José Carlos de Magalhães), 2017, 237 p.; Antonio Eduardo Reichmann Seixas. Princípios Unidroit para contratos de longa duração (Mestrado, sob orientação de Maristela Basso), 2019, 161 p. 
dúbios ou limítrofes de duas subáreas, continuam sendo referenciados, no presente artigo, em notas de rodapé, como se fez no item anterior.

O quartel se inicia com a apresentação de uma única dissertação de mestrado no ano de 1997, de autoria de Eduardo Lameirão Roncolatto. Intitulada "Os limites da jurisdição brasileira: a extraterritorialidade e seus princípios informativos”, a dissertação foi orientada por José Carlos de Magalhães e conta com 180 páginas.

No ano seguinte, 1998, a tese de Doutorado do hoje Professor Associado do Departamento de Direito Internacional e Comparado, José Augusto Fontoura Costa, que ministra a disciplina no curso de Graduação, é apresentada, sob orientação de Hermes Marcelo Huck. Intitulada "Aplicação uniforme do direito uniforme", a tese conta 313 páginas. No mesmo ano, sob orientação de José Carlos de Magalhães, a dissertação de Mestrado de Giovanni Barontini é apresentada, analisando, em 170 páginas, a "Dissolução do vínculo conjugal no âmbito internacional".

No ano 2000, Orlando Celso da Silva Neto apresentou, sob orientação de Paulo Borba Casella, a dissertação de mestrado intitulada "Unificação do direito processual civil internacional: as normas unificadoras de cooperação jurídica no Mercosul e na União Europeia”, em 284 páginas.

Em 2001, Antonio Benedito do Nascimento, orientado por José Carlos de Magalhães, apresenta tese de Doutorado, com 308 páginas intitulada " $\mathrm{O}$ juiz da infância e da juventude e o direito internacional". No mesmo ano, Antenor Pereira Madruga Filho, sob orientação de João Grandino Rodas, depositou sua tese de Doutorado intitulada "Renúncia à imunidade de jurisdição pelo Estado brasileiro", com 483 páginas.

Em 2002, Inez Lopes Matos Carneiro de Farias apresenta a dissertação de mestrado intitulada "A proteção do consumidor internacional no comércio internacional eletrônico", sob orientação de José Carlos de Magalhães, em 294 páginas. Neste ano, o mesmo orientador assistiu ao depósito da dissertação de mestrado de José Setti Diaz, intitulada "Contratos eletrônicos: aspectos relativos à validade, formação, lei aplicável e jurisdição dos contratos entre empresas e entre estas e seus consumidores", em 187 páginas.

Em 2004, sob orientação de Georgette Nacarato Nazo, José Aparecido Rigato apresentou sua Tese de Doutorado de 226 páginas intitulada "Adoção internacional: o princípio da subsidiariedade na Convenção da Haia de 1993: uma proposta tipológica". No mesmo ano, Thiago Luchesi, sob orientação de Maristela Basso, depositou sua dissertação de mestrado intitulada "Aspectos de direito internacional privado relacionados à propriedade intelectual”, em 155 páginas.

No ano de 2005, Áurea Christine Tanaka, sob orientação de Masato Ninomiya apresenta sua Tese de Doutorado intitulada "Princípios aplicáveis ao divórcio no direito internacional privado: o caso dos brasileiros no Japão”, versada em 293 
páginas. No mesmo ano, Mariana Masson, sob orientação de Maristela Basso, depositou sua dissertação de mestrado intitulada "A arbitrabilidade objetiva na perspectiva do direito brasileiro em face da promulgação do decreto 4.311/02 (Convenção de Nova Iorque $^{22}$ )", em 185 páginas. Na área de concentração de Direito Civil, Wilson Donizeti Liberati, sob orientação de Roberto João Elias, defendia a tese de Doutorado "Adoção internacional: a autoridade central na Convenção de Haia", 23 com 194 páginas.

2006 começa com a apresentação, na Área de Concentração de Direito do Trabalho, da dissertação de Mestrado de 99 páginas intitulada "Transferência internacional de empregados: lei aplicável e foro competente", de Andrei Fernandes de Oliveira, sob orientação de Oris de Oliveira. Já no âmbito da Área de Concentração de Direito Comercial, Helen Carla Caiado Naves, sob orientação de Haroldo Malheiros Duclerc Verçosa, apresentou a dissertação - que foi classificada sob a rubrica de Direito Internacional Privado, intitulada "Contratos bancários internacionais: reflexões sobre aplicabilidade no Brasil”, em 114 páginas.

$\mathrm{Na}$ área de concentração de Direito Internacional, o ano de 2006 assiste o depósito da dissertação de mestrado de Marcelo André Bulgueroni, que, sob orientação de Paulo Borba Casella e em 114 páginas, discorreu sobre "O contrato internacional eletrônico".

Em 2008 se verifica a apresentação, na Área de Concentração de Direito do Trabalho, da Tese de Doutorado de 247 páginas intitulada "Contrato internacional de trabalho: acesso à justiça", de Antonio Galvão Peres, sob orientação de Estevão Mallet.

Por sua vez, na área de concentração de Direito Internacional, o ano de 2008 assiste o depósito da Tese de Doutorado de Gustavo Ferraz de Campos Monaco, que, sob orientação de João Grandino Rodas e em 212 páginas, discorreu sobre "Atribuição da guarda e suas consequências em direito internacional privado". ${ }^{24}$ No mesmo ano, Renato Covelo apresentou sua dissertação de mestrado, sob orientação de Masato Ninomiya, tencionando uma "Contribuição ao estudo do regime jurídico da navegação aérea”, em 188 páginas.

Em 2009, Daniel Cabral Gruenbaum apresenta sua Tese de Doutorado, sob orientação de Paulo Borba Casella, intitulada "O reconhecimento e a extensão da autoridade da sentença estrangeira”, com 152 páginas.

\footnotetext{
22 Nova Iorque é uma cidade localizada no estado do Maranhão. Nova York é a grafia correta da cidade-sede da Organização das Nações Unidas.

23 Haia é um acidente geográfico, pedindo artigo. O correto é da Haia.

24 MONACO, Gustavo Ferraz de Campos. Guarda Internacional de Crianças. São Paulo: Quartier Latin, 2012.
} 
Em 2010, Flávio Augusto Picchi apresenta sua Dissertação de Mestrado, também sob orientação de Paulo Borba Casella, em 180 páginas, e que procura tecer uma "Contribuição à análise econômica do direito internacional privado".

No ano de 2012, Luiz Fabricio Thaumaturgo Vergueiro deposita, sob orientação e André de Carvalho Ramos, a Tese de Doutorado intitulada "Implementação da cooperação jurídica internacional vertical”, de 271 páginas. No mesmo ano, sob orientação de José Carlos de Magalhães, Carlos Alberto Vilela Sampaio deposita sua dissertação de mestrado, com 175 páginas, que recebeu o título "Reconhecimento da sentença e do laudo arbitral estrangeiros”. Já Gabriel Mattos Tavares Valente dos Reis deposita sua dissertação de mestrado orientada por Paulo Borba Casella, com 128 páginas que clamam "Por uma análise cosmopolita da determinação do direito aplicável".

Tendo defendido minha Tese de Livre-docência, e recebido o Título, por unanimidade, em janeiro de 2013, comecei a lecionar na pós-graduação matérias atinentes ao direito internacional privado, temática que estava desde há muitos anos fora do catálogo das disciplinas oferecidas no Programa. Desde então, e de forma quase ininterrupta, tenho ofertado, algumas vezes com a colaboração da Professora Associada Cláudia Perrone-Moisés, outras vezes com a colaboração de colegas estrangeiros, sobretudo portugueses e franceses, ao menos uma disciplina no Programa. ${ }^{25}$

Em 2013, Vera Cecília Monteiro de Barros deposita, sob orientação de Wagner Luiz M. Lino, sua dissertação de Mestrado, que recebe o título "Homologação para o reconhecimento ou execução da sentença arbitral estrangeira no Brasil: exceção de ofensa à ordem pública", de 238 páginas. No mesmo ano, e sob orientação de André de Carvalho Ramos, Luis Vanderlei Pardi deposita sua dissertação de mestrado, de 193 páginas, intitulada "O regime jurídico da expulsão de estrangeiro no país, à luz da Constituição Federal e dos tratados de direitos humanos".

25 No último quinquênio (2016 a 2021) ministrei as seguintes disciplinas no Pós-Graduação, perfazendo um total de 88 créditos, a saber: $2016 / 1^{\circ}$ sem: Cultura, Constituição e Direito Internacional Privado (conjuntamente com a Professora Associada Cláudia Perrone-Moisés); 2016/2 ${ }^{\circ}$ sem: Ordenamento e Direito Internacional Privado ou Âmbito de Eficácia e Âmbito de Competência das Leis; 2017/1요 sem: em gozo de licença-prêmio; 2017/2 ${ }^{\circ}$ sem: Aspectos da Unificação Regional do Direito Internacional Privado. O Direito Internacional Privado da União Europeia (com participações de inúmeros docentes europeus); 2017/2 ${ }^{\circ}$ sem: Cultura, Constituição e Direito Internacional Privado (conjuntamente com a Professora Associada Cláudia Perrone-Moisés); 2018/1º sem: Princípios Fundamentais do Direito Internacional Privado da Família (conjuntamente com o Professor Hugues Fulchiron - Université Lyon 3 - e a Professora Associada Cláudia Perrone-Moisés); 2018/2 ${ }^{\circ}$ sem: Direito Internacional Privado do Esporte; 2018/2 ${ }^{\circ}$ sem: Ordenamento e Direito Internacional Privado ou Âmbito de Eficácia e Âmbito de Competência das Leis; 2019/1 $1^{\circ} \mathrm{sem}$ : Temas clássicos (logo, fundamentais) de Direito Internacional Privado; 2019/2 $\mathrm{sem}$ : Cultura, Constituição e Direito Internacional Privado (conjuntamente com a Profa. Associada Cláudia Perrone-Moisés); 2020/1 ${ }^{\circ}$ sem: Proteção Internacional e os Direitos da Criança; 2020/2 ${ }^{\circ}$ sem: Temas clássicos (logo, fundamentais) de Direito Internacional Privado. 
No ano de 2014, com dissertação relacionada à condição jurídica do estrangeiro, Anamara Osório Silva trata da "Dupla incriminação no direito internacional contemporâneo: análise sob a perspectiva do processo de extradição”, em 153 páginas. O mestrado foi orientado por André de Carvalho Ramos. Por sua vez, Luiz Philipe Ferreira de Oliveira, sob orientação de Masato Ninomiya, deposita sua dissertação de mestrado de 73 páginas sobre "Adoção internacional e nacionalidade: um estudo comparado Brasil e Japão". Viviane Ceolin Dallasta Del Grossi, sob orientação de Paulo Borba Casella, defendeu a dissertação de mestrado intitulada "A defesa na cooperação jurídica internacional penal", com 244 páginas.

Em 2015, Solano de Camargo é o primeiro de meus orientandos a defender sua dissertação de mestrado, de 204 páginas, intitulada "Forum shopping: modo lícito de escolha da jurisdição?”. No mesmo ano, sob orientação de Alberto do Amaral Junior, Daniel Arbix defende sua tese de Doutorado que, em 250 páginas, aborda a "Resolução on-line de controvérsias: tecnologias e jurisdições".

No ano de 2016, Gabriel Mattos Tavares Valente dos Reis, dando continuidade a suas pesquisas do mestrado, deposita sua tese de Doutorado orientada também por Paulo Borba Casella, e em 203 páginas propõe que se dê a "Aplicação do direito estrangeiro sob a ótica cosmopolita". Por sua vez, Thiago Rocha da Fonseca, sob orientação de José Carlos de Magalhães, deposita sua dissertação de mestrado acerca da "Autonomia da vontade e eleição de lei aplicável nos contratos internacionais do comércio”, com 142 páginas. Já Saulo Stefanone Alle, sob orientação de André de Carvalho Ramos, deposita sua Tese de Doutorado acerca do "Auxílio direto ativo em matéria penal no Brasil: dever internacional de cooperar, conflitos interpretativos e lei aplicável”, com 216 páginas.

No mesmo ano, e ambos sob minha orientação de mestrado, José Luiz Souza de Moraes deposita sua dissertação intitulada "Uniões entre pessoas do mesmo gênero no direito internacional privado", com 223 páginas, e Manuel Nabais da Furriela deposita "A aplicabilidade pelo Brasil da convenção sobre os aspectos civis do sequestro internacional de crianças”, com 91 páginas. Também sob minha orientação, e no mesmo ano, Jannice Amóras Monteiro deposita sua Tese de Doutorado que, em 121 páginas, versa "A aquisição de imóveis rurais por pessoa jurídica brasileira com maioria do capital social estrangeiro".

No ano de 2017, Jean Eduardo Batista Nicolau, em Programa de DuplaTitulação com a Universidade de Lyon 3, Jean Moulin, deposita e defende a Tese de Doutorado intitulada "Direito internacional Privado do Esporte: estudos sobre uma disciplina em construção”. A orientação da tese, de 443 páginas, coube a Hugues Fulchiron, pelo lado francês, e a mim, pelo lado brasileiro. No mesmo ano, dois de meus mestrandos também depositaram suas dissertações: Ivo de Paula Medaglia, "O direito aplicável ao 
mérito das controvérsias internacionais submetidas à arbitragem”, com 192 páginas, e Kim Modolo Diz, "Reenvio e convergência do direito aplicável”, com 88 páginas.

Ainda em 2017, Carlos Walter Marinho Campos Neto, deposita seu Mestrado, em 189 páginas, sobre a "Interpretação da Convenção de Haia" ${ }^{26}$ sobre os aspectos civis do sequestro internacional de crianças", sob orientação de André de Carvalho Ramos.

Em 2018, Gustavo Henrique Campos Souza, sob minha orientação, deposita sua dissertação de mestrado intitulada "A efetivação do melhor interesse por meio dos mecanismos de participação da criança no direito internacional privado da família", com 142 páginas. Já Carlos Alberto Vilela Sampaio, sob orientação de José Carlos de Magalhães, deposita sua Tese de Doutorado intitulada "Mecanismos de cooperação jurídica internacional e sua aplicabilidade no Brasil", com 208 páginas. Ainda no mesmo ano, e sob a orientação de Maristela Basso, Sandro de Oliveira deposita sua dissertação de mestrado que tem por título "A tutela jurisdicional localizadora: uma abordagem processual substantiva de direito internacional privado", em 394 páginas. Por sua vez, Fernanda Garibaldi Barreto de Oliveira, sob orientação de Maristela Basso, deposita sua dissertação intitulada “O método conflitual clássico à luz da internacionalização do direito e desafios e perspectivas do direito internacional privado", com 184 páginas. Marina Freire, sob orientação de Paulo Borba Casella, defendeu a dissertação e mestrado sobre "Conflito de competência: o caso da Convenção da Haia sobre os aspectos civis do sequestro internacional de crianças”, com191 páginas. Caio Eduardo von Dreifus, com orientação de João Grandino Rodas, depositou sua dissertação de mestrado intitulada "A participação de credores internacionais em processo de recuperação judicial: o caso Sete Brasil”, com 173 páginas.

Em 2019, sob orientação de Umberto Celli Junior, Paula Christine Schlle deposita sua Tese de Doutorado acerca da "Cooperação internacional em matéria de resolução bancária”, com 234 páginas. André Cordelli Alves, sob orientação de João Grandino Rodas, depositou a tese "Contratos de construção internacionais - Modelo Contratual Fidic New Red Book: utilização sob o contexto de civil law e compatibilidade com o sistema legal brasileiro", com 322 páginas.

No mesmo ano, sob minha orientação, Liv Azevedo Sarmento e Marina de Campos Sanz Ronchi defendem suas dissertações de mestrado, respectivamente, sobre "A gestação de substituição e seus desafios no direito internacional privado", com 163 páginas, e "Escolha das leis aplicáveis nos contratos plurilocalizados: direito brasileiro e fontes internacionais", com 128 páginas. Também sob minha orientação, Analluza Bolivar Dallari depositou sua Tese de Doutorado, com 215 páginas, e que procurou

$26 \quad$ Veja-se a nota 22, supra. 
defender o "Balizamento do contrato de pesquisa clínica por normas de aplicação imediata: estudo do regime jurídico brasileiro". Por sua vez, Solano de Camargo, sob coorientação da Professora Helena Mota, da Universidade do Porto e minha, defendeu a Tese de Doutorado "Jurisdições anômalas: ordem pública processual e homologação de sentenças estrangeiras", com 263 páginas.

Os dados de 2020, em razão da Pandemia, não foram ainda lançados no sistema Dedalus. Não obstante, faço aqui menção das dissertações e teses de cujas bancas eu participei. Sob minha orientação, Nadja Ponte Nogueira, André Marinho Marianetti Braga e Amanda Cunha e Mello Smith Martins defenderam suas dissertações de mestrado, respectivamente, sobre "Expulsão de estrangeiro: repensando um instituto antigo", com 132 páginas, "Tolerância e direito internacional privado", com 159 páginas e "Privacidade, proteção de dados e danos transnacionais: aspectos do direito internacional privado brasileiro”, com 264 páginas. Também sob minha orientação, José Luiz Souza de Moraes, defendeu sua Tese de Doutorado intitulada "A ordem pública no direito internacional privado da família: parâmetros constitucionais”, com 297 páginas.

Em 2021, consigo atestar, por serem meus orientandos, apenas o depósito das teses de Doutorado de Kim Modolo Diz e Henrique Lenon Farias Guedes. A tese de Diz, intitulada "Os conflitos de qualificação no direito internacional privado", com 115 páginas, está agendada para ser defendida em 18 de março. Por sua vez, a tese de Guedes, intitulada "Normas de aplicação imediata e arbitragem trabalhista: entre pluralismo e transnacionalidade", com 217 páginas, deverá ser defendida em 17 de março.

Conclui-se, assim, que neste segundo quartel do PPGD mantido pela FDUSP, a subárea de Direito Internacional Privado foi bastante mais produtiva, pese embora a ausência de dissertações e teses apresentadas, na subárea, nos anos de 1999, 2003, 2007 e 2011. ${ }^{27}$ Nestes últimos 25 (vinte e cinco) anos foram elaboradas pelo menos sessenta dissertações de Mestrado e trinta e nove teses de Doutorado que abordam temas típicos da subárea, ainda que duas dissertações e duas teses tenham sido elaboradas em outras áreas de concentração, como Direito Civil (uma tese), Direito Comercial (uma dissertação) e Direito do Trabalho (uma dissertação e uma tese).

Além disso, duas teses de Livre-Docência e duas outras apresentadas a concursos para provimento de cargos de Professor Titular na subárea de Direito Internacional Privado foram apresentadas à Faculdade de Direito da USP, contribuindo para o aprofundamento dos temas afetos a esta subárea.

Veja-se a nota 19, supra, com produção sobre arbitragem, em 2007 e 2011, e a nota 20, supra, com produção sobre contratos em 1999, 2003 e 2007. 
À guisa de conclusão: o futuro esperado para a subárea

O levantamento dos dados compilados acima demonstra que a produção cresceu de forma intensa a partir de 1997, quando se procede à comparação com o quartel anterior, iniciado em 1971 e concluído em 1996.

Uma das possíveis razões para a menor produção no primeiro quartel está vinculada, certamente com a Resolução $n^{0} 3$ do Conselho Federal de Educação, aprovada em 1972, e que estabeleceu novo currículo para os cursos de direito. Por sua letra, o ensino do Direito Internacional foi reduzido à condição de disciplina opcional, algo que jamais tinha acontecido na história do país. Nem mesmo em outros períodos ditatoriais. ${ }^{28}$ Cada instituição de ensino deveria optar por duas dentre oito das disciplinas arroladas na categoria de opcionais, a saber: Ciências das Finanças e Direito Financeiro (Tributário e Fiscal); Direito Agrário; Direito da Navegação (Marinha e Aeronáutica); Direito Internacional Privado; Direito Internacional Público; Direito Previdenciário; Direito Romano e Medicina Legal. Por outro lado, tal regra foi modificada em 1994, pela Portaria MEC $n^{\circ} 1.886 / 94$, que reintroduziu o estudo do direito internacional no Eixo das disciplinas profissionalizantes. $\mathrm{O}$ interstício de exclusão do rol das disciplinas obrigatórias provocou danos indeléveis na pesquisa da disciplina. Sua reintrodução, todavia, pode explicar o interesse redobrado dos pesquisadores no segundo quartel do PPGD.

Além disso, o aumento do corpo docente e a expansão de vagas de orientação no primeiro decênio do século XXI também contribuíram de forma decisiva para a absorção dos pós-graduandos interessados na subárea.

Mas, e estou convicto quanto a este ponto, foram a oferta consistente e insistente de vagas exclusivas para a subárea e o oferecimento de disciplinas de pósgraduação, associados a uma pesquisa sólida e direcionada empreendida pelos docentes do PPGD-FDUSP vinculados à subárea o fator que mais parece ter contribuído para a difusão de temas afetos aos quatro objetos clássicos do Direito Internacional Privado (conflitos de leis no espaço, conflitos de jurisdição, nacionalidade e condição jurídica do estrangeiro).

28 Muito embora o regime estabelecido em 1930 tenha tentado introduzir um ensino jurídico mais técnico e profissionalizante, o que pretendia ser alcançado com o deslocamento de certas disciplinas como o Direito Romano, a Filosofia do Direito e o Direito Internacional Privado para o curso autônomo do Doutorado, que visava garantir a formação de professores para os cursos superiores de Direito. A Revolução Constitucionalista de 1932, todavia, impediu a total implementação da reforma idealizada pelo então Ministro da Educação e Saúde Pública do Governo Provisório, Francisco Campos. A respeito, veja-se PÁDUA; Lilian Silvana Perilli de; COSTA, Alessandra D. M. da. Uma abordagem histórica sobre as políticas curriculares para os cursos jurídicos. Disponível em: http://www.histedbr.fe.unicamp.br/ acer_ histedbr/seminario/seminario8/_files/PGI8bBCS.doc. Acesso em: 8 jul. 2019. 
De minha parte, imbuído que fui do compromisso institucional de me dedicar à disciplina do Direito Internacional Privado - e, consequentemente, à subárea existente no PPGD - cumpre-me assumir o público compromisso de continuar fomentando o ensino, a pesquisa e a produção científica de qualidade afetas à subárea do Direito Internacional Privado junto à área de concentração em Direito Internacional do Programa de Pós-Graduação em Direito mantido pela Faculdade de Direito da Universidade de São Paulo, o que farei pelo próximo quartel e por mais seis anos, até minha aposentadoria compulsória, se for ela a que vier me colher. 